\title{
EFFECT OF PKP ON SERUM SOST IN PATIENTS WITH VERTEBRAL COMPRESSION FRACTURES
}

\section{EFEITO DE PKP EM SOST SORO EM PACIENTES COM FRATURAS DE COMPRESSÃO VERTEBRAL}

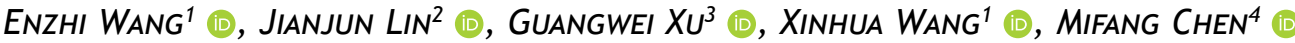 \\ 1. Taizhou Integrated Chinese and Western Medicine Hospital, Department of Clinical Laboratory, Taizhou, Zhejiang, China. \\ 2. Ningbo Fourth Hospital, Department of Clinical Laboratory, Ningbo, Zhejiang, China. \\ 3. Ningbo Women and Children's Hospital, Department of Orthopedics, Ningbo, Zhejiang, China. \\ 4. Ningbo Women and Children's Hospital, Department of Clinical Laboratory, Ningbo, Zhejiang, China.
}

\section{ABSTRACT}

Objective: This study sought to determine serum sclerostin (SOST) expression in patients with osteoporotic thoracolumbar vertebral compression fractures before and after percutaneous kyphoplasty (PKP). Methods: Serum SOST levels were quantified with a sandwich enzyme-linked immunosorbent assay (ELISA) preoperatively and six months postoperatively. Anterior vertebral height, kyphotic angles, and Visual Analogue Scale (VAS) scores were also recorded. Results: Serum SOST was highly expressed in patients and remained negatively correlated with bone mineral density (BMD). Vertebral heights, local kyphotic angles, and VAS scores were all significantly improved after PKP. However, serum SOST was positively correlated with BMD six months after surgery. Conclusion: PKP was an effective treatment strategy for osteoporotic thoracolumbar vertebral compression fractures, improving BMD and decreasing serum SOST levels. Level of Evidence II, Prospective comparative study.

Keywords: Bone Density. Kyphoplasty. Osteoporosis.

\section{RESUMO}

Objetivo: Este estudo teve por objetivo determinar a expressão de esclerostina (SOST) em pacientes com fraturas vertebrais osteoporóticas por compressão na coluna toracolombar antes e depois da Cifoplastia Percutânea (PKP). Métodos: Os níveis de SOST no soro foram quantificados por meio de um Ensaio de Imunoadsorção Ligado à Enzima (ELISA) sanduíche, realizado no pré-operatório e aos seis meses pós-operatório. Foram também registrados a altura do corpo vertebral anterior, os ângulos cifóticos, e os valores obtidos na escala analógica visual (VAS). Resultados: O nível de SOST no soro foi altamente expresso nos pacientes, e permaneceu correlacionado negativamente com a densidade mineral óssea (DMO). As alturas vertebrais, os ângulos cifóticos locais, e as pontuações obtidas na escala VAS foram significativamente melhores após o PKP. No entanto, o SOST foi correlacionado positivamente com a DMO aos seis meses pós-operatório. Conclusão: O PKP foi uma estratégia eficaz para o tratamento de fraturas vertebrais osteoporóticas por compressão na coluna toracolombar, melhorando os níveis de DMO e diminuindo os níveis de SOST no soro. Nível de Evidência II, Estudo prospectivo comparativo.

Descritores: Densidade Óssea. Cifoplastia. Osteoporose.

Citation: Wang E, Lin J, Xu G, Wang X, Chen M. Effect of pkp on serum sost in patients with vertebral compression fractures. Acta Ortop Bras. [online]. 2020;28(6):323-326. Available from URL: http://www.scielo.br/aob.

\section{INTRODUCTION}

Osteoporosis is a common skeletal disease characterized by low bone mass, impaired bone mechanical functions, and increased bone fragility. It has become a major cause of disability and death among older adults, leading to an increased fracture risk. ${ }^{1}$ Vertebral fracture is the most common outcome of osteoporosis, especially osteoporotic vertebral compression fractures (OVCF), which frequently occur at the thoracolumbar segment. ${ }^{2}$ Patients with that type of fracture usually suffer from low back and lumbosacral pain that is aggravated by activities.

We believe osteoporotic fracture is traditionally treated with bed rest and analgesics. However, long-term bed rest might result in potential complications such as pulmonary infection, atelectasis, thrombosis, and pulmonary embolism. ${ }^{3}$ Open surgery and minimally

All authors declare no potential conflict of interest related to this article.

The study was conducted at Ningbo Women and Children's Hospital.

Correspondence: Mifang Chen. Liuting St, 339, Haishu District, Ningbo, Zhejiang, China, 315031. mifangchen@126.com 
invasive surgery are well documented alternative methods for the operative treatment of OVCF. Open surgeries, such as laminectomy and internal fixation, are appropriate for patients who present signs of neurological deficits, or those with space-occupying lesions in spinal canal and spinal cord compression, based on nerve computed tomography (CT) and magnetic resonance imaging (MRI) scans. However, open surgery entails two major disadvantages: greater blood loss and high failure rate. ${ }^{4}$

Percutaneous kyphoplasty (PKP) is a vertebroplasty-modified minimally invasive procedure that may effectively recover height and reduce bone cement leakage. ${ }^{5}$ Up to now, few studies evaluated PKP efficacy in the treatment of osteoporotic thoracolumbar vertebral compression fractures. ${ }^{6-8}$

Sclerostin (SOST) is an important osteocyte-derived glycoprotein that functions as a negative regulator of bone formation by inhibiting Wnt/ $\beta$-catenin signaling to promote osteogenic differentiation. ${ }^{9}$ SOST-KO mice showed to enhance bone defects healing ${ }^{10}$ and highly expressed serum SOST is associated with fracture healing. ${ }^{11}$ SOST functions as a therapeutic target for treating osteoporotic fracture. ${ }^{12}$ However, the influence of PKP treatment on SOST expression remained unclear. Considering that, this study sought to analyze the serum SOST expression among patients with osteoporotic thoracolumbar vertebral compression fractures and their response to PKP treatment.

\section{MATERIALS AND METHODS}

Chart 1. Highlights.

Serum SOST was highly expressed in patients with osteoporotic thoracolumbar vertebral compression fractures.

Vertebral heights, Cobb's angles, and VAS scores were significantly improved after PKP

Postoperative SOST was positively correlated with BMD during 6 months follow-up

\section{Study population}

From January 2017 to June 2018, 150 patients with osteoporotic fractures examined by computed tomography (CT) or magnetic resonance imaging (MRI) of the thoracolumbar spine were evaluated. Of these, sixty cases of thoracolumbar vertebral compression fractures were included in the study. Patients with severe heart and lung disease and coagulation disorders were excluded. Our study group included 33 women and 27 men with body mass index (BMI) ranging from 22 to $28 \mathrm{~kg} / \mathrm{m}^{3}$. Average age at surgery was 69 years (range: 44 to 78 years) and average duration of symptoms was eight weeks (range: 2 to 24 weeks). Sixty gender- and age-matched individuals with normal bone mineral density (BMD), confirmed by physical examination during the same period, composed the control group. A written informed consent form was obtained from each participant. All experimental protocols for this study were approved by the Ethics Committee of Ningbo Women and Children's Hospital.

\section{Surgical procedure}

Percutaneous kyphoplasty (PKP) was performed under general anesthesia in prone position, as previously described. ${ }^{13}$ Bone marrow biopsy needle was percutaneously inserted under C-arm fluoroscopy guidance (BAITENG Medical, Shanghai, China) into the fractured vertebra body through pedicle. Then a balloon was inserted into the vertebra to restore vertebral body height and create a cavity for bone cement injection. Bone cement introducer was removed after the cement was well diffused. The same surgeons performed all operations, and no bone cement leakage and balloon rupture occurred during operation.

\section{Enzyme-linked immunosorbent assay}

Fasting blood samples containing anticoagulant were collected from patients with thoracolumbar vertebral compression fractures and healthy volunteers and centrifuged at $3000 \mathrm{rpm}$ for twenty minutes. Serum specimens were then stored at $-80^{\circ} \mathrm{C}$ until analysis. Serum sclerostin (SOST) protein levels in serum were measured using the Human SOST ELISA kit (Boster, Wuhan, China), according to manufacturer's instruction.

\section{Clinical and radiographic examinations}

Values of bone mineral density (BMD), visual analogue scale (VAS), anterior vertebral body height of the fractured level (AVHF), and Cobb's angle were investigated to evaluate improvement in patients' pain and outcomes. BMD was measured by dual energy X-ray absorptiometry using the QDR-2000 (Hologic Inc., Waltham, MA, USA). Clinical evaluation of pain employed the VAS score, ranging from 0 (no pain) to 10 (severe pain). X-ray examination was obtained preoperatively and one-week postoperatively. Cobb's angle was measured between the superior vertebral endplate, one level above the treated vertebra, and the inferior vertebral body endplate, one level below the treated vertebra. Anterior height was determined by measuring the length between the superior endplate most antero-superior point and the inferior endplate most antero-inferior point of the fractured vertebra body.

\section{Statistical analysis}

Data were expressed as mean \pm standard deviation (SD) and analyzed using SPSS version 22.0 (SPSS, Chicago, IL, USA). Statistical differences were assessed using two-sided Student's $t$ test or analysis of variance, and $p$ value $<0.05$ was considered significantly different. Spearman's rank correlation coefficient was used to analyze the correlation between serum SOST and BMD.

\section{RESULTS}

SOST and BMD association in patients with osteoporotic thoracolumbar vertebral compression fractures

Patients with osteoporotic thoracolumbar vertebral compression fractures showed higher serum SOST (Figure 1A, $p<0.05$ ) and lower BMD (Figure 1B, $p<0.05$ ) than healthy controls. We found a significant negative correlation between serum SOST and $\mathrm{BMD}$, according to Spearman's correlation coefficient (Figure 1C, $r=0.5345, p<0.001$ ). 
A

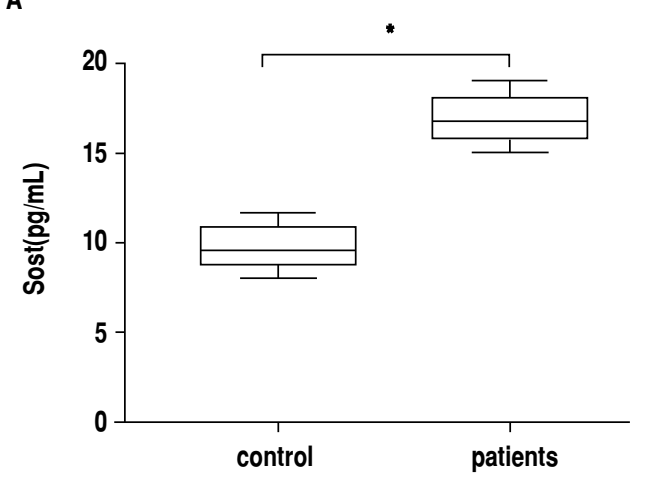

B

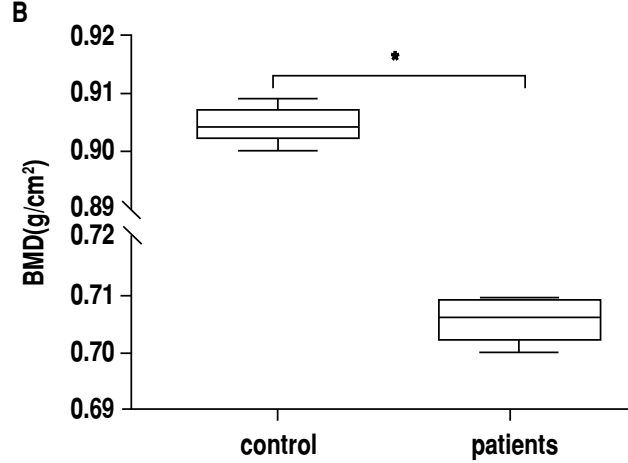

C

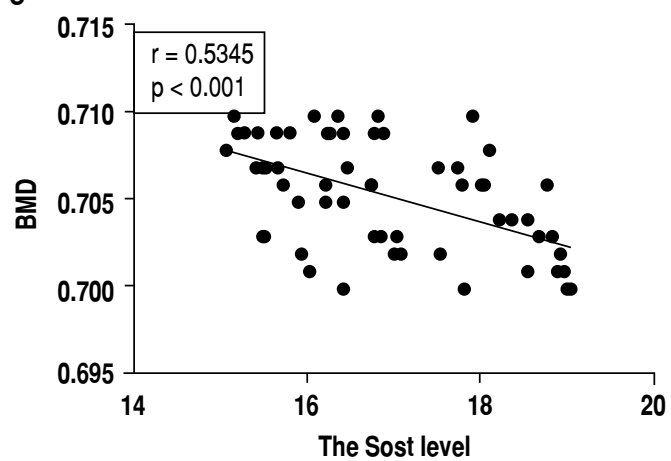

Figure 1. Sclerostin expression in patients with osteoporotic thoracolumbar vertebral compression fractures and its correlation with bone mineral density. $p<0.05$ vs. control group.

A: serum SOST levels; B: BMD in patients with osteoporotic thoracolumbar vertebral compression fractures and healthy controls; and C: correlation analysis between serum SOST and BMD in patients with osteoporotic thoracolumbar vertebral compression fractures.

\section{Pre- and postoperative outcomes comparisons}

All patients underwent successful surgery. Mean operative time was seventy minutes (range 45 120 minutes). Intraoperative blood loss ranged from 8 to $14 \mathrm{~mL}$, with an average of $10 \mathrm{~mL}$. All patients were able to get out of bed within 3 to 5 days after surgery. Forty-six cases reported complete pain relief, 12 partial relief, and two no relief; complete remission rate was $96.60 \%$. Patients developed no complications such as constipation, pneumonia, and lower extremities deep venous thrombosis.

As presented in Table 1, the average preoperative pain based on VAS was $7.24(S D=0.29)$ and the average postoperative VAS was $2.24(S D=0.14)$, suggesting pain relief one week after PKP. We also observed postoperative improvement in the anterior vertebral height and a significant decrease in the average vertebral Cobb's angle when compared towith preoperative values (all, $p<0.05$ ).
Table 1. Pre- and postoperative Visual Analogue Scale, anterior vertebral height, and Cobb's angle.

\begin{tabular}{c|c|c|c}
\hline Group & VAS & $\begin{array}{c}\text { anterior vertebral } \\
\text { height }(\mathrm{mm})\end{array}$ & Cobb's angle $\left(^{\circ}\right)$ \\
\hline preoperative & $7.24 \pm 0.29$ & $18.47 \pm 0.82$ & $23.72 \pm 1.15$ \\
\hline postoperative & $2.24 \pm 0.14^{*}$ & $24.38 \pm 1.62^{*}$ & $8.84 \pm 1.42^{*}$ \\
\hline
\end{tabular}

Postoperative SOST expression in patients and its correlation with BMD

To better understand the efficacy of PKP for treating thoracolumbar vertebral compression fractures and its effect on SOST expression, we compared serum SOST levels and BMD before and after surgery. Figure 2 shows that serum SOST was markedly downregulated (Figure 2A) while BMD shows an upward trend (Figure 2B) at one, three and six months postoperatively in comparison to preoperative values (all, $p<0.05$ ). We found a positive correlation between serum SOST level and BMD within six-month postoperative (Table 2, $p<0.05$ ).

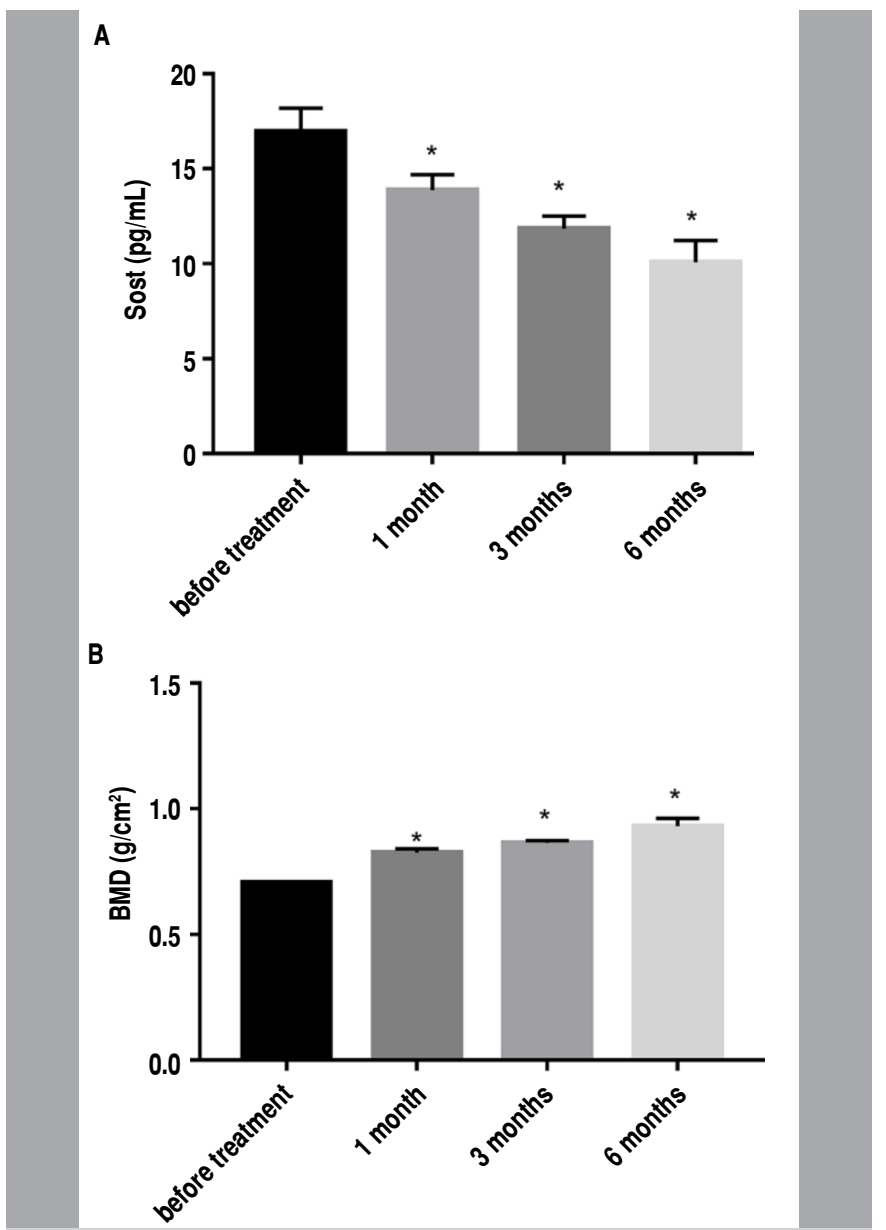

Figure 2. Changes of serum sclerostin and bone mineral density after percutaneous kyphoplasty.

A: serum SOST levels; and B: BMD before surgery and at one, three and six months postoperatively.

Table 2. Correlation between serum sclerostin and postoperative bone mineral density.

\begin{tabular}{c|c|c}
\hline Postoperative & $\mathbf{r}$ & $\mathbf{P}$ \\
\hline one month & 0.269 & 0.037 \\
\hline three months & 0.621 & 0.000 \\
\hline six months & 0.629 & 0.000 \\
\hline
\end{tabular}




\section{DISCUSSION}

Osteoporosis vertebral compression fracture (OVCF), a common complication of osteoporosis, may lead to severe lower back pain, limited movement, and spinal and kyphotic deformity. ${ }^{14}$ Bone remodeling mainly relies on the activity of two major cells types - bone-forming osteoblasts and bone-resorbing osteoclasts. Recently, accumulating evidence strongly implied that Wnt/ $\beta$-catenin signaling plays an important role in controlling bone mass, increasing proliferation and differentiation of osteoblastic precursor cells and improving bone mineral density (BMD). ${ }^{15}$

In mammalian cells, Serum sclerostin (SOST) inhibits Wnt signaling by binding to Wnt receptors extracellular domain. ${ }^{16}$ Thus, SOST is increasingly recognized as a vital negative regulator of bone formation. ${ }^{17}$ SOST deficiency-induced diseases in humans are characterized by increased bone mass. ${ }^{18}$ Gaudio and colleagues ${ }^{19}$ found high SOST serum levels expression in patients with immobilization-induced bone loss. According to Shen et al., ${ }^{20}$ anti-SOST is a potential therapy for osteoporosis. In our study, SOST serum levels were significantly higher in patients with osteoporotic thoracolumbar vertebral compression fractures when compared with healthy controls. More importantly, serum SOST was negatively correlated with BMD.
With the continuous socioeconomic development and the improvement in medical technology, serveral surgical methods are used for treating thoracolumbar fractures. ${ }^{21,22}$ Percutaneous kyphoplasty (PKP) is a minimally invasive, safe, and effective treatment for OVCF that can effectively and quickly relieve pain, improve functional capacity, reduce the incidence of complications, increase vertebral strength, avoid postoperative vertebral height loss, and prevent secondary fractures. ${ }^{23}$ Sun et al. ${ }^{24}$ reported low-viscosity for PKP results in the restoration of middle vertebral height for treating OVCF. Zhao et al. ${ }^{25}$ found PKP to be also associated with a significantly longer operation time and a lower risk of cement leakage. In our study, all patients showed significant improvement in VAS score, anterior vertebral height, and Cobb's angle within one week after operation compared with values before operation. PKP surgery also resulted in serum SOST downregulation and BMD increase at 6-month follow-up. SOST was positively correlated with BMD after PKP treatment.

\section{CONCLUSION}

In conclusion, PKP treatment may not only restore compressed vertebral body height and correct kyphosis, but also reduce SOST expression to achieve an effective treatment of patients with osteoporotic thoracolumbar vertebral compression fractures.

AUTHORS' CONTRIBUTIONS: Each author contributed individually and significantly to the development of this article. EW: designed the study; JL: designed the study; GX: conducted the experiments and analyzed the data; XW: conducted the experiments and analyzed the data; MC: conducted most of the experiments and wrote the manuscript.

\section{REFERENCES}

1. Cauley JA. Osteoporosis: fracture epidemiology update 2016. Curr Opin Rheu matol. 2017;29(2):150-6.

2. Jun DS, An BK, Yu CH, Hwang KH, Paik JW. Practical use of bone scan in patients with an osteoporotic vertebral compression fracture. J Korean Med Sci. 2015;30(2):194-8.

3. Lee JH, Lee JH, Jin Y. Surgical techniques and clinical evidence of vertebroplasty and kyphoplasty for osteoporotic vertebral fractures. Osteoporos Sarcopenia. 2017;3(2):82-9.

4. Shi GH, Li PC, Wei XC. [Progress on treatment of osteoporotic vertebral compression fracture]. Zhongguo Gu Shang. 2013;26(10):878-82.

5. Liu H, Wang S, Liu T, Meng B, He F, Zhou R, et al. Incremental temperature cement delivery technique may prevent cement leakage in metastatic vertebral lesions. J Orthop Surg. 2017;25(3):2309499017718931.

6. Wang X, Tan L, Lin X, Wu C, Zeng J, Hu H. [Photoelectric guided navigation unilateral puncture of the percutaneous kyphoplasty in treatment of thoracolumbar osteoporotic vertebral compression fracture]. Zhongguo Xiu Fu Chong Jian Wai Ke Za Zhi. 2018;32(2):203-9.

7. Liu T, Li Z, Su Q, Hai Y. Cement leakage in osteoporotic vertebral compression fractures with cortical defect using high-viscosity bone cement during unilateral percutaneous kyphoplasty surgery. Medicine. 2017;96(25):e7216.

8. Ru XL, Jiang ZH, Gui XG, Sun QC, Song BS, Lin H, et al. [Complications of percutaneous kyphoplasty non-related with bone leakage in treating osteoporotic thoracolumbar vertebral compression fractures]. Zhongguo Gu Shang. 2015;28(8):763-7.

9. Xu Y, Wang L, Sun Y, Han X, Gao T, Xu X, et al. Sclerostin is essential for alveolar bone loss in occlusal hypofunction. Exp Ther Med. 2016;11(5):1812-8.

10. Mcgee-Lawrence ME, Ryan ZC, Carpio LR, Kakar S, Westendorf JJ, Kumar R. Sclerostin deficient mice rapidly heal bone defects by activating $\beta$-catenin and increasing intramembranous ossification. Biochem Biophys Res Commun. 2013;441(4):886-90.

11. Sarahrudi K, Thomas A, Albrecht C, Aharinejad S. Strongly enhanced levels of sclerostin during human fracture healing. J Orthop Res. 2012;30(10):1549-55.

12. Suen PK, Qin L. Sclerostin, an emerging therapeutic target for treating osteoporosis and osteoporotic fracture: a general review. J Orthop Translat. 2015;4:1-13.

13. Liu B, Gan F, Ge Y, Yu H. Clinical efficacy analysis of percutaneous kyphoplasty combined with zoledronic acid in the treatment and prevention of osteoporotic vertebral compression fractures. J Invest Surg. 2018;31(5):1-6.
14. Svensson HK, Olofsson EH, Karlsson J, Hansson T, Olsson LE. A painful, never ending story: older women's experiences of living with an osteoporotic vertebral compression fracture. Osteoporos Int. 2016;27:1729-36.

15. Bodine PVN, Robinson JA, Bhat RA, Billiard J, Bex FJ, Komm BS. The role of Wnt signaling in bone and mineral metabolism. Clin Rev Bone Miner Metab. 2006;4:73-96.

16. Lu K, Li YX, Shi TS, Yu F, Min SC, Qiao L, et al. Changes in expression of Wnt signaling pathway inhibitors dickkopf-1 and sclerostin before and after total joint arthroplasty. Medicine. 2017;96:e8082.

17. He G, Shi Y, Lim J, Bellido T, Ni J, Long F. Differential involvement of Wnt signaling in Bmp regulation of cancellous versus periosteal bone growth. Bone Res. 2017;5:17016.

18. Mcclung MR. Sclerostin antibodies in osteoporosis: latest evidence and therapeutic potential. Ther Adv Musculoskelet Dis. 2017;9(10):263-70.

19. Agostino G, Pietra P, Cornelia B, Venerando T, Brigitte L, Mangiafico RA, et al. Increased sclerostin serum levels associated with bone formation and resorption markers in patients with immobilization-induced bone loss. J Clin Endocrinol Metab. 2010;95(5):2248-53.

20. Shen J, Meyers CA, Shrestha S, Singh A, LaChaud G, Nguyen V, et al. Sclerostin expression in skeletal sarcomas. Human Pathology 2016;58:24-34.

21. Li K, Zhong L, Ren X, Hui X, Wen Z, Luo D, et al. Effect of the percutaneous pedicle screw fixation at the fractured vertebra on the treatment of thoracolumbar fractures. Int Orthop. 2016;40:1103-10.

22. Yi HJ, Jeong JH, Im SB, Lee JK. Percutaneous vertebroplasty versus conservative treatment for one level thoracolumbar osteoporotic compression fracture: results of an over 2-year follow-up. Pain Physician. 2016;19(5):E743-50.

23. Feng $H$, Huang $P$, Zhang $X$, Zheng $G$, Wang $Y$. Unilateral versus bilateral percutaneous kyphoplasty for osteoporotic vertebral compression fractures: a systematic review and meta-analysis of RCTs. J Orthop Res. 2015;33(11):1713-23.

24. Sun K, Liu Y, Peng H, Tan JF, Zhang M, Zheng XN, et al. A comparative study of high-viscosity cement percutaneous vertebroplasty vs. low-viscosity cement percutaneous kyphoplasty for treatment of osteoporotic vertebral compression fractures. Hua Zhong Ke Ji Da Xue Bao Yi Xue Ying De Wen Ban. 2016;36(3):389-94.

25. Zhao G, Liu X, Li F. Balloon kyphoplasty versus percutaneous vertebroplasty for treatment of osteoporotic vertebral compression fractures (OVCFs). Osteoporos Int. 2016;27(9):2823-34. 